Prepared for the U.S. Department of Energy

under Contract DE-AC05-76RL01830

\title{
Pressure Systems Stored-Energy Threshold Risk Analysis
}

SS Paulsen

August 2009

Pacific Northwest

NATIONAL LABORATORY

Proudly Operated by Battelle Since 1965 


\title{
DISCLAIMER
}

This report was prepared as an account of work sponsored by an agency of the United States Government. Neither the United States Government nor any agency thereof, nor Battelle Memorial Institute, nor any of their employees, makes any warranty, express or implied, or assumes any legal liability or responsibility for the accuracy, completeness, or usefulness of any information, apparatus, product, or process disclosed, or represents that its use would not infringe privately owned rights. Reference herein to any specific commercial product, process, or service by trade name, trademark, manufacturer, or otherwise does not necessarily constitute or imply its endorsement, recommendation, or favoring by the United States Government or any agency thereof, or Battelle Memorial Institute. The views and opinions of authors expressed herein do not necessarily state or reflect those of the United States Government or any agency thereof.

\author{
PACIFIC NORTHWEST NATIONAL LABORATORY \\ operated by \\ BATTELLE \\ for the \\ UNITED STATES DEPARTMENT OF ENERGY \\ under Contract DE-AC05-76RL01830
}

Printed in the United States of America

Available to DOE and DOE contractors from the Office of Scientific and Technical Information,

P.O. Box 62, Oak Ridge, TN 37831-0062; ph: (865) 576-8401 fax: (865) 576-5728 email: reports@adonis.osti.gov

Available to the public from the National Technical Information Service, U.S. Department of Commerce, 5285 Port Royal Rd., Springfield, VA (800) 553-6847 fax: (703) 605-6900 email: orders@ntis.fedworld.gov online ordering: http://www.ntis.gov/ordering.htm

22161 ph:

This document was printed on recycled paper. 


\section{Pressure Systems Stored-Energy Threshold Risk Analysis}

SS Paulsen

August 2009

Prepared for

the U.S. Department of Energy under Contract DE-AC05-76RL01830

Pacific Northwest National Laboratory

Richland, Washington 99352 



\section{Summary}

Federal Regulation 10 CFR 851, which became effective February 2007, brought to light potential weaknesses regarding the Pressure Safety Program at the Pacific Northwest National Laboratory (PNNL). The definition of a pressure system in 10 CFR 851 does not contain a limit based upon pressure or any other criteria. Therefore, the need for a method to determine an appropriate risk-based hazard level for pressure safety was identified. The Laboratory has historically used a stored energy of $1000 \mathrm{lbf}$-ft to define a pressure hazard; however, an analytical basis for this value had not been documented. This document establishes the technical basis by evaluating the use of stored energy as an appropriate criterion to establish a pressure hazard, exploring a suitable risk threshold for pressure hazards, and reviewing the methods used to determine stored energy. The literature review and technical analysis concludes the use of stored energy as a method for determining a potential risk, the $1000 \mathrm{lbf}$-ft threshold, and the methods used by PNNL to calculate stored energy are all appropriate. Recommendations for further program improvements are also discussed. 



\section{Contents}

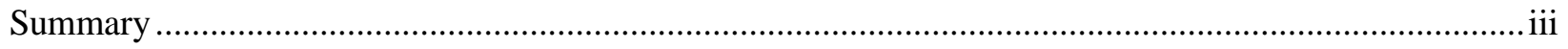

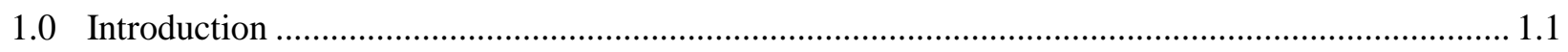

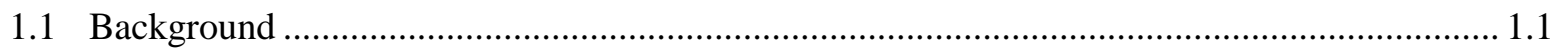

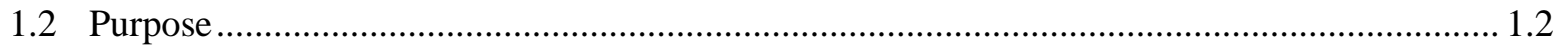

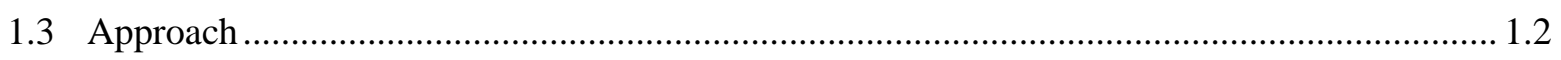

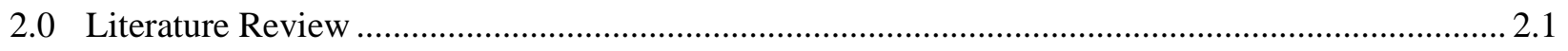

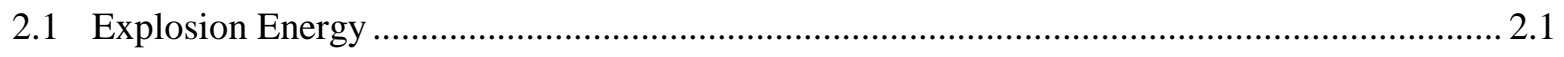

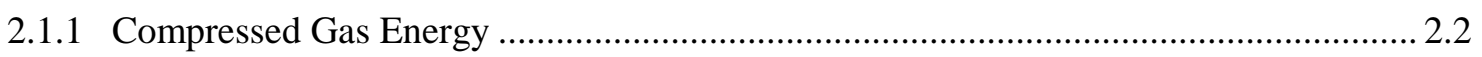

2.1.2 Energy in Liquids Below Boiling Point ........................................................................ 2.3

2.1.3 Energy for Non-Ideal Gas, Vapor, and Flashing Liquid ............................................ 2.3

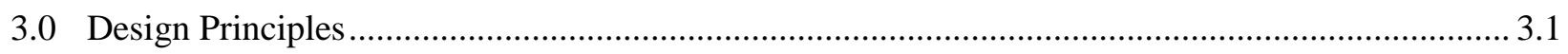

3.1 Basic Overpressure Design Principles …............................................................................... 3.1

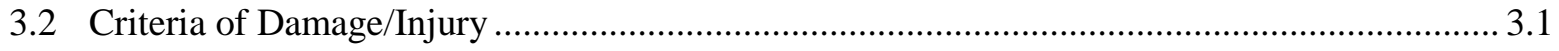

3.3 Determining the Blast Wave Pressure.............................................................................. 3.1

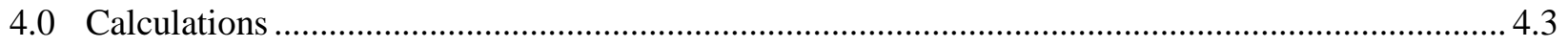

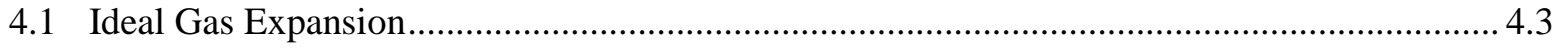

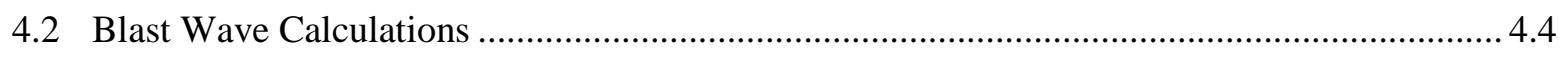

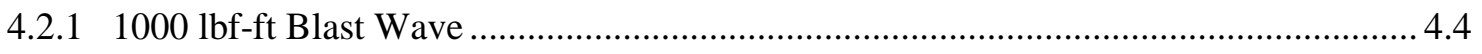

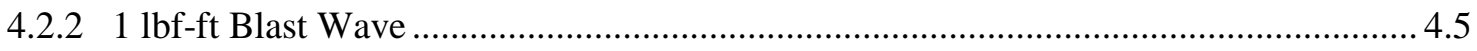

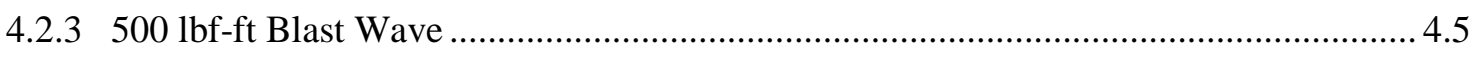

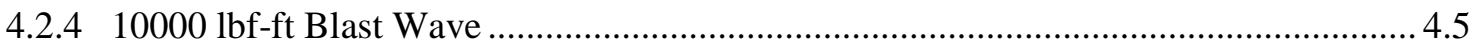

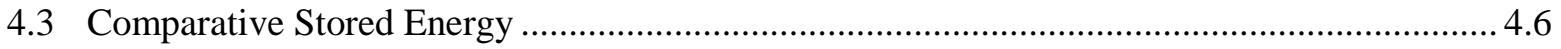

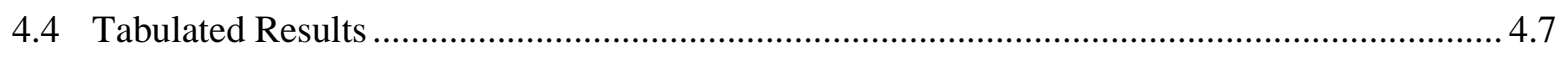

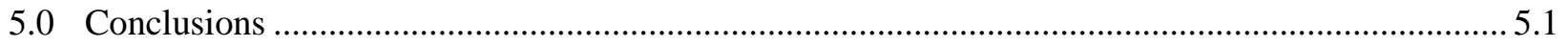

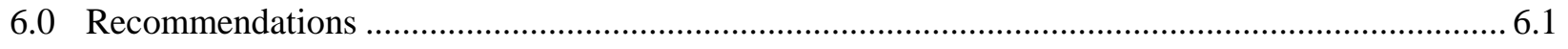

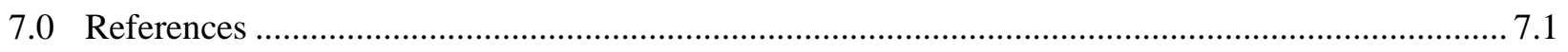

Appendix A Internet Articles Regarding Flash Powder Energy ....................................................... A.1 


\section{Tables}

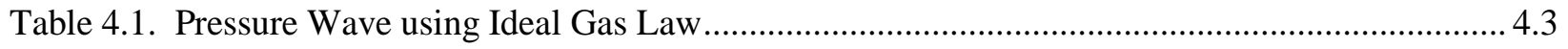

Table 4.2. Stored Energy of Everyday Items ....................................................................................... 4.6

Table 4.3. Tabulated Stored Energy Analysis Results ........................................................................... 4.7 


\subsection{Introduction}

\subsection{Background}

Title 10, Part 851, Code of Federal Regulations (10 CFR 851) establishes worker safety and health requirements to govern contractor activities on U.S. Department of Energy (DOE) sites. This regulation went into effect on February 9, 2007. Pressure Safety is one of the disciplines specifically covered by this regulation, as detailed in Appendix A, Section 4. Section 851.3 defines pressure systems as "all pressure vessels, and pressure sources including cryogenics, pneumatic, hydraulic, and vacuum. Vacuum systems should be considered pressure systems due to their potential for catastrophic failure due to backfill pressurization. Associated hardware (e.g., gauges, and regulators), fittings, piping, pumps, and pressure relief devices are also integral parts of the pressure system.”

Appendix A, Section 4 states "contractors must establish safety policies and procedures to ensure that pressure systems are designed, fabricated, tested, inspected, maintained, repaired, and operated by trained and qualified personnel in accordance with applicable and sound engineering principles.” The regulation goes on to state that all pressure systems and components shall conform to the applicable American Society of Mechanical Engineers (ASME) Boiler and Pressure Vessel Code, ASME B31 (Code for Pressure Piping), and the strictest applicable state and local codes. Part (c) further states, "When national consensus codes are not applicable (because of pressure range, vessel geometry, use of special materials, etc.), contractors must implement measures to provide equivalent protection and ensure a level of safety greater than or equal to the level of protection afforded by the ASME or applicable state or local code. Measures must include the following:

(1) Design drawings, sketches, and calculations must be reviewed and approved by a qualified independent design professional (i.e., professional engineer). Documented organizational peer review is acceptable.

(2) Qualified personnel must be used to perform examinations and inspections of materials, in-process fabrications, non-destructive tests, and acceptance test.

(3) Documentation, traceability, and accountability must be maintained for each pressure vessel or system, including descriptions of design, pressure conditions, testing, inspection, operation, repair, and maintenance.”

Pacific Northwest National Laboratory has implemented a graded approach to Pressure System safety based upon the level of risk associated with varying categories of pressure systems to conform to the regulation. There is no pressure limit or other variable defining a pressure system in 10 CFR 851. Therefore, PNNL has established a pressure system level based upon stored energy, which poses minimal risk to PNNL staff during operations.

Stored energy has been used by PNNL as the basis for recognizing a significant pressure risk for over 20 years. Historically, multiple approaches have been implemented throughout the DOE Complex for pressure related risk identification and an inter-laboratory consensus standard has not been developed. The existing threshold limit at PNNL is $1000 \mathrm{lbf}-\mathrm{ft}$ of stored energy. Below this limit there are minimal requirements and no formal approvals are required. The stored energy has historically been calculated for gases or vapors above the boiling point by assuming isentropic expansion as shown in equation 1.1 (Lindeburg 2001). 


$$
\mathrm{W}=\frac{\mathrm{P}_{1} \cdot \mathrm{V}_{1}}{\mathrm{k}-1}\left[1-\left(\frac{\mathrm{P}_{2}}{\mathrm{P}_{1}}\right)^{\frac{(1-\mathrm{k})}{\mathrm{k}}}\right]
$$

Where:

$$
\begin{aligned}
& \mathrm{W}=\text { Work Energy } \\
& \mathrm{k}=\text { Ratio of Specific Heats } \\
& \mathrm{P}_{1}=\text { Initial Pressure } \\
& \mathrm{P}_{2}=2^{\text {nd }} \text { State Pressure } \\
& \mathrm{V}_{1}=\text { Initial Volume }
\end{aligned}
$$

For liquids below their boiling point, the stored energy is calculated using the bulk modulus of the liquid, or a conservative value if one is unknown. Equation 1.2 was implemented at PNNL due to its use in the Lawrence Livermore National Laboratory (LLNL) Pressure Safety Manual.

$$
\mathrm{W}=\frac{1}{2} \cdot \beta \cdot \mathrm{P}^{2} \cdot \mathrm{V}
$$

Where:

$$
\begin{aligned}
& W=\text { Work Energy } \\
& V=\text { Initial Volume } \\
& \beta=\text { Compressibility (1/Bulk Modulus) } \\
& P=\text { Pressure }
\end{aligned}
$$

\subsection{Purpose}

The purpose of this analysis is to show that establishing $1000 \mathrm{lbf}-\mathrm{ft}$ store energy as the upper boundary for pre-approved pressure systems is a reasonable, and more importantly, safe approach that limits the hazards associated with pressure systems while not impeding research.

The remainder of this document will:

- Evaluate the use of stored energy as an appropriate hazard criterion.

- Evaluate the methods used to determine stored energy.

- Establish an acceptable level of risk, or threshold value, with regard to operation of pressure systems.

Note: Formal approval to design and operate pressure equipment that is below the acceptable risk level is not required (i.e., this type of system is considered minimal-action as defined by PNNL).

\subsection{Approach}

The approach taken within this analysis to accomplish the three purposes was to:

- Review literature regarding compressed gas stored energy and consequences from an overpressure event. 
- Use an alternative method for determining blast wave pressure based upon gas expansion per the Ideal Gas Law as a baseline check of the values obtained by more extravagant methods.

- Evaluate the effects of a resultant blast wave pressure for a given stored energy versus relevant consequence criteria. The stored energies evaluated were $1000 \mathrm{lbf}-\mathrm{ft}, 1 \mathrm{lbf}-\mathrm{ft}, 500 \mathrm{lbf}-\mathrm{ft}$, and 10000 lbf-ft.

- Compare stored energy for typical items encountered at home and in a laboratory versus the 1000 lbf-ft threshold to evaluate if this value is reasonable. 



\subsection{Literature Review}

A review of Lees' Loss and Prevention in the Process Industries, the Fire Protection Handbook (FPH), twentieth edition, Los Alamos National Laboratory (LANL) policy P101-34, Pressure, Vacuum, and Cryogenic Systems, ASME PCC-2 - 2008 Repair of Pressure Equipment and Piping, and the LLNL Pressure System and Design Manual reveals stored energy is a widely used method to evaluate pressure risk. Methods for determining the stored energy due to gas expansion, liquid compression, non-ideal gas, vapor, and flashing liquid are discussed in various sections of each document.

Three major hazards are associated with pressure systems—-fire, explosion, and toxic release. At PNNL, fire and toxic hazard mitigation are integrated into the Pressure Safety Program through the Chemical Process and Pressure Systems Permit processes, by the proposed integration of compressed gas pipe codes into the PNNL Engineering Standards, and Fire Protection Engineer reviews.

Lees’ (2005) states, “Explosions in the process industries cause fewer serious accidents than fire but more than toxic release. When [toxic releases do] occur, however, they often inflict greater loss of life and damage than fire. Explosion is usually regarded as having disaster potential greater than that of fire but less than that of toxic release.” This document focuses on the explosive hazard associated with pressure systems.

\subsection{Explosion Energy}

An explosion is a rapid and violent release of energy that produces potentially damaging pressures. Lees' (2005) breaks down explosions into 3 main types—-physical energy, chemical energy, and nuclear energy. Nuclear explosions are not a part of this analysis.

"Physical energy may take such forms as pressure energy in gases, strain energy in metals, or electrical energy. Examples of the violent release of physical energy are the explosion of a vessel due to high gas pressure and the sudden rupture of a vessel due to brittle fracture (Lees' 2005).” Thermal energy is usually linked to failure, but does not contribute to explosion energy. For example, accidental flashing of a superheated liquid due to pressure reduction or introducing a fluid to a surface with a temperature well above its boiling point has explosive potential.

Lees' continues, “Chemical energy derives from a chemical reaction. Examples of the violent release of chemical energy are explosion of a vessel due to combustion of flammable gas, and explosion of a reactor caused by decomposition of reaction products in a runaway chemical reaction. Chemical explosions are either (1) uniform explosions or (2) propagating explosions. An explosion in a vessel tends to be a uniform explosion, while an explosion in a long pipe gives a propagating explosion. (2005)” Note: Chemical explosions potential is limited at PNNL by Fire Protection Engineering policies and procedures, such as the Chemical Process Permit.

Lees' Section 17.4 discusses stored energy in great detail. Lees' references the equations PNNL currently uses for gas expansion stored energy and liquid expansion energy. Section 17.4.4 discusses vessel metal strain energy and concludes "the elastic strain energy of the metal is usually small compared with the chemical and fluid expansion energies (Lees' 2005),” and is therefore excluded from this analysis. 
The following sections discuss in greater detail calculating stored (explosive) energy for ideal gas expansion, liquid compression, non-ideal gas, vapor, and flashing liquid.

\subsubsection{Compressed Gas Energy}

Lees' Section 17.4.5 discusses vessel burst energy for ideal gases. Four separate equations (2.1 - 2.4) from this section and their validity for compressed gas expansion are discussed below.

$$
\mathrm{E}_{\mathrm{Br}}=\frac{\left(\mathrm{P}_{1}-\mathrm{P}_{0}\right) \cdot \mathrm{V}}{\mathrm{k}-1}
$$

Brode

$$
\mathrm{E}_{\mathrm{Ba}}:=\frac{\mathrm{P}_{1} \cdot \mathrm{V}_{1}}{\mathrm{k}-1}\left[1-\left(\frac{\mathrm{P}_{0}}{\mathrm{P}_{1}}\right)^{\frac{(\mathrm{k}-1)}{\mathrm{k}}}\right]
$$

Baker (isentropic; consistent with PNNL Stored Energy Worksheet)

$$
\mathrm{E}_{\mathrm{Ki}}=\mathrm{nRT} \cdot \ln \left(\frac{\mathrm{P}_{1}}{\mathrm{P}_{0}}\right)
$$

Kinney

$$
E_{A G}=\frac{P_{1} \cdot V_{1}-P_{0} \cdot V_{2}}{k_{1}-1}+\frac{P_{0} \cdot\left(V_{2}-V_{1}\right)}{k_{0}-1}
$$

Aslanov-Golinsky

Where:

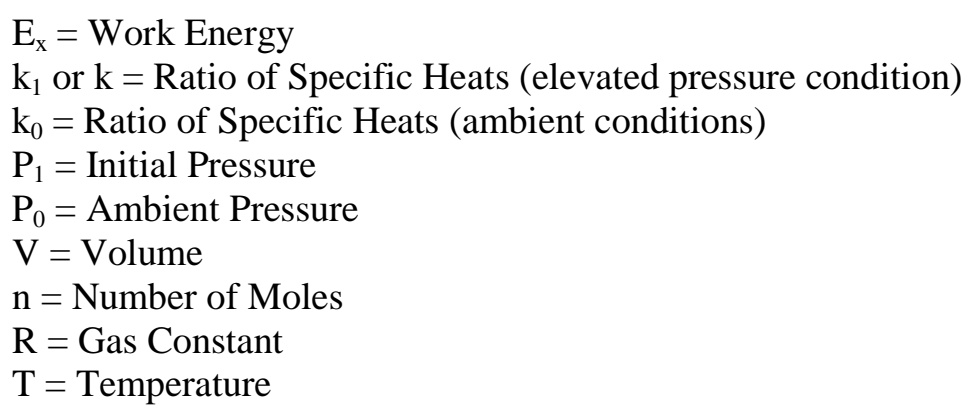

Comparisons of the expressions for the energy of explosions given by Strehlow and Ricker (1976) and the Center of Chemical Process Safety (1994/15) both recommend the use of the Brode equation (2.1). The main alternative equation is that of Baker (2.2), which is used by PNNL, Idaho National Laboratory, LLNL, and historically by LANL. Furthermore, ASME PCC-2, Article 5.1, Appendix II (2008) uses a form of Baker to calculate the stored energy for pneumatic pressure testing. Lees' Figure 17.6 and the associated discussion states “....the values yielded by the other expressions (Author's Note: Equations 2.3 and 2.4 above) tend to those of the Brode equation at higher pressures... (Lees' 2005).”

The findings in Lees' that indicate stored energy is an appropriate method to determine the consequences of a compressed gas overpressure event are supported in the FPH. Section 2, Chapter 8, 
“Explosions,” states, “A burst pressure vessel releases its energy of compression in the time it takes for a crack to propagate sufficiently far to allow the metal shell to split open. This is typically on the order of 10 microseconds. The peak pressure is approximately equal to the vessel pressure at the time of bursting, Pb (FPH 2008)." Similarly, the FPH uses the Brode equation (2.1) to generate a theoretical stored energy.

\subsubsection{Energy in Liquids Below Boiling Point}

Liquids are much less compressible than gases when exposed to pressure, and therefore a different method for calculation of stored energy is required. Calculation of the stored energy for liquids below the boiling point is discussed in Lees' Section 17.4.3. Lees' uses the same equation recommended by LLNL and that is currently used at PNNL (equation 1.2). This calculation of stored energy for liquids below their boiling point is based upon an experimentally established compressibility of the liquid. The compressibility is equal to 1/Bulk Modulus of the liquid, which is similar to the Modulus of Elasticity for a solid.

\subsubsection{Energy for Non-Ideal Gas, Vapor, and Flashing Liquid}

Because non-ideal gases, vapors, and flashing liquids are more complex substances, a single equation cannot be derived to establish a theoretical stored energy based upon pressure, volume, and temperature alone. Lees' Section 17.4.6 describes vessel burst energy for non-ideal gas, vapor, and flashing liquid. In this case, the energy of the explosion is obtained from the difference in the internal energy between the initial and final states assuming an isentropic expansion using suitable thermodynamic diagrams or tables. 



\subsection{Design Principles}

\subsection{Basic Overpressure Design Principles}

The basic instances that induce an overpressure event are exceeding the design failure pressure or a material imperfection failure at the operating pressure. At PNNL, standard practice is to design to the maximum allowable working pressure (MAWP) of the minimum rated component in any given section of a pressure system. Pressure relief is generally installed whenever there is a potential to exceed the MAWP when the stored energy is above 1000 lbf-ft unless there are extenuating circumstances (e.g., addition of a relief valve could add too much volume space for extremely sensitive experiments with low volume requirements and other protections have been put in place). The pressures used for determining the stored energy in a system are defined, at PNNL, as follows:

Maximum possible pressure should be the lowest of the following:

- $\quad$ Maximum Supply Pressure (Bottle Pressure, Pump Dead Head, Thermal Expansion)

- 1.2 x Relief Device Set Point (valves cannot be between protected device and relief device)

- 1.2 x Component Burst Pressure (for worst case stored energy component).

Another area that merits mention is the effect of temperature on stored energy due to the direct affect it has on the stored energy in a system. The potential to add heat is considered as another source of pressurizing a system due to thermal expansion when determining the maximum possible supply pressure. Heating of closed containers is prohibited unless explicit` approvals are granted and appropriate administrative controls are put in place.

\subsection{Criteria of Damage/Injury}

The causes of explosion injury to a person include the blast wave, missiles, thermal effects, and toxic effects. This analysis is concerned with physical explosions; therefore, thermal effects (fire) and toxic effects are not discussed in great detail because PNNL implements other policies and procedures to mitigate the possibility of fire and toxic releases. Typically research processes take place in ventilated enclosures or are separated from staff when flammable or toxic hazards are present.

The modes of physical explosion injury of interest are eardrum rupture, lung hemorrhage, and missile injury. These types of injury are evaluated based upon the probability of injury. For each type of injury, a threshold value has been established at which there is approximately a $1 \%$ chance of injury. Multiple studies have been conducted for each type of injury and are discussed in Lees' Section 17.38 and 17.39 and Section 2, Chapter 8 of the FPH. Lees' data indicates a minimum threshold for ear drum rupture at 2.4 psig and lung hemorrhage at 14.5 psig whereas the FPH lists 5.1 psig and 29 psig respectively.

\subsection{Determining the Blast Wave Pressure}

Pressure propagating away from an explosion is usually referred to as a blast wave. As the blast wave moves away from the release point, the shock amplitude decreases due to atmospheric resistance, and the time duration of the pressure disturbance increases. Both Lees' and FPH discuss the calculation of a blast 
wave by utilizing an equivalent energy in terms of TNT (trinitrotoluene). Various correlations and theoretical models of ideal blasts waves show that the shock pressure can be correlated with an energyscaled distance consistent with:

$$
\frac{\mathrm{z}}{\mathrm{E}^{.333}}=\frac{\mathrm{z}}{\mathrm{W}_{\mathrm{TNT}}{ }^{.333}}
$$

Where:

$$
\begin{aligned}
& Z=\text { Distance from explosion site } \\
& E=\text { Blast wave energy } \\
& W_{\text {TNT }}=\text { TNT equivalent weight for the same blast wave energy }
\end{aligned}
$$

Table 2.8.1 in the FPH shows the consequences of representative values for overpressure and the associated TNT equivalent scaled distance.

Note: The TNT equivalence method for determining blast wave consequences was discussed with PNNL Fire Protection Engineering staff. This method is considered conservative per Fire Protection Engineering with relation to compressed gas expansion during an overpressure event. 


\subsection{Calculations}

This section explores blast waves in relation to various stored energy situations. Calculations are performed using equation 2.2 (Baker) to determine the pressure wave propagation. The ultimate purpose of the calculation is to validate $1000 \mathrm{lbf}-\mathrm{ft}$ as a reasonable limit when determining a pressure hazard.

\subsection{Ideal Gas Expansion}

An attempt to determine the pressure at a distance from an over-pressurized vessel (Table 4.1) was calculated using a form of the Ideal Gas Law, where $\mathrm{P}_{1} \cdot \mathrm{V}_{1}=\mathrm{P}_{2} \cdot \mathrm{V}_{2}$ (aka, Boyle's Law). This method acts as a baseline check of other methods used to calculate the blast wave of an over-pressure event. First, the required pressure to generate $1000 \mathrm{lbf}-\mathrm{ft}$ in a sphere with a given diameter was calculated. The diameters evaluated are below 6" because diameters greater than this are governed by the ASME Boiler and Pressure Vessel Code. These starting pressures and volumes resulting in $1000 \mathrm{lbf}-\mathrm{ft}$ of stored energy were used to determine the pressure at a given distance assuming consistent expansion.

Table 4.1. Pressure Wave using Ideal Gas Law

The pressure wave is determined based upon the ideal gas law, where P1V1 = P2V2 V1 and V2 are assumed to be spherical, due to pressure wave of an explosion point. Brittle Materials are not allowed for use with compressed gas, and therefore only a point explosion is reasonable. (Based upon a beginning sphere of air pressure, $k=1.4$ that results in $1000 \mathrm{lbf}-\mathrm{ft}$ )

\begin{tabular}{|r|r|r|r|r|r|r|r|r|r|r|}
\hline & Volume 1 & $\begin{array}{l}\text { Volume, } \\
\text { in^3 at }\end{array}$ & $\begin{array}{l}\text { listance } \\
\text { (inch) }\end{array}$ & & & & & & \\
\hline Diameter & cu-in & 1 & 2 & 3 & 4 & 5 & 6 & & 8 & 10 \\
\hline 0.0625 & $1.28 \mathrm{E}-04$ & 5 & 35 & 117 & 274 & 533 & 919 & 2170 & 4228 & 7295 \\
\hline 0.125 & $1.02 \mathrm{E}-03$ & 5 & 37 & 120 & 281 & 543 & 933 & 2195 & 4268 & 7352 \\
\hline 0.25 & $8.18 \mathrm{E}-03$ & 6 & 40 & 128 & 294 & 564 & 963 & 2247 & 4348 & 7467 \\
\hline 0.5 & $6.54 \mathrm{E}-02$ & 8 & 48 & 144 & 322 & 606 & 1023 & 2352 & 4511 & 7700 \\
\hline 1 & 0.52 & 14 & 65 & 180 & 382 & 697 & 1150 & 2572 & 4849 & 8181 \\
\hline 1.5 & 1.77 & 22 & 87 & 221 & 449 & 796 & 1288 & 2806 & 5204 & 8682 \\
\hline 2 & 4.19 & 34 & 113 & 268 & 524 & 905 & 1437 & 3054 & 5575 & 9203 \\
\hline 3 & 14.14 & 65 & 180 & 382 & 697 & 1150 & 1767 & 3591 & 6371 & 10306 \\
\hline 4 & 33.51 & 113 & 268 & 524 & 905 & 1437 & 2145 & 4189 & 7238 & 11494 \\
\hline 5 & 65.45 & 180 & 382 & 697 & 1150 & 1767 & 2572 & 4849 & 8181 & 12770 \\
\hline 6 & 113.10 & 268 & 524 & 905 & 1437 & 2145 & 3054 & 5575 & 9203 & 14137 \\
\hline
\end{tabular}

Absolute Pressure Pressure Resultant (psi) for $1000 \mathrm{lbf}-\mathrm{ft}$

\begin{tabular}{|r|r|r|r|r|r|r|r|r|r|r|}
\hline 0.0625 & 40000000 & 1113 & 146 & 44 & 19 & 10 & 5.56 & 2.36 & 1.21 & 0.70 \\
\hline 0.125 & 4900000 & 997 & 136 & 42 & 18 & 9 & 5.37 & 2.28 & 1.17 & 0.68 \\
\hline 0.25 & 620000 & 850 & 126 & 40 & 17 & 9 & 5.27 & 2.26 & 1.17 & 0.68 \\
\hline 0.5 & 80000 & 640 & 110 & 36 & 16 & 9 & 5.12 & 2.23 & 1.16 & 0.68 \\
\hline 1 & 11000 & 407 & 88 & 32 & 15 & 8 & 5.01 & 2.24 & 1.19 & 0.70 \\
\hline 1.5 & 3450 & 272 & 70 & 28 & 14 & 8 & 4.73 & 2.17 & 1.17 & 0.70 \\
\hline 2 & 1560 & 195 & 58 & 24 & 12 & 7 & 4.55 & 2.14 & 1.17 & 0.71 \\
\hline 3 & 535 & 116 & 42 & 20 & 11 & 7 & 4.28 & 2.11 & 1.19 & 0.73 \\
\hline 4 & 258 & 76 & 32 & 17 & 10 & 6 & 4.03 & 2.06 & 1.19 & 0.75 \\
\hline 5 & 152 & 55 & 26 & 14 & 9 & 6 & 3.87 & 2.05 & 1.22 & 0.78 \\
\hline 6 & 101 & 43 & 22 & 13 & 8 & 5 & 3.74 & 2.05 & 1.24 & 0.81 \\
\hline
\end{tabular}

Distances from the edge of the vessel that are of interest based upon this approach are 1) at 3 inches the maximum pressure is 44 psig ( pressure for lung hemorrhage), 2) at 6 inches the maximum pressure is 5.56 psig ( pressure for ear drum rupture), and 3 ) at 12 inches the maximum pressure is 0.81 psig (less than the pressure required for missile debris). 


\subsection{Blast Wave Calculations}

The approach presented by Lees' and in FPH is used to determine the blast wave propagation and potential consequence as outlined in Chapter 8, Section 2 of the FPH.

\subsubsection{0 lbf-ft Blast Wave}

The blast wave for an over-pressure event in a system with $1000 \mathrm{lbf}-\mathrm{ft}$ is calculated using a 4 inch sphere as an example pressure vessel:

$$
\begin{aligned}
& \mathrm{r}:=2 \cdot \text { in } \\
& \mathrm{V}_{1}:=\frac{4 \cdot \pi \cdot \mathrm{r}^{3}}{3}=33.51 \mathrm{in}^{3} \\
& \mathrm{P}_{0}:=15 \cdot \mathrm{psi} \quad \text { Atmospheric Pressure } \\
& \mathrm{P}_{1}:=260 \cdot \mathrm{psi} \quad \text { Vessel Pressure (245 psig) } \\
& \mathrm{k}:=1.4 \quad \text { Ratio of Specific Heats for Air } \\
& \mathrm{E}_{\mathrm{Ba}}:=\frac{\mathrm{P}_{1} \cdot \mathrm{V}_{1}}{\mathrm{k}-1}\left[1-\left(\frac{\mathrm{P}_{0}}{\mathrm{P}_{1}}\right)^{\frac{(\mathrm{k}-1)}{\mathrm{k}}}\right] \\
& \mathrm{E}_{\mathrm{Ba}}=1372 \mathrm{~J} \text { converts to } \mathrm{E}_{\mathrm{Ba}}=1012 \cdot \mathrm{lbf} \cdot \mathrm{ft} \quad \text { Energy } \\
& \mathrm{E}_{\mathrm{TNT}}:=4850 \cdot \frac{\mathrm{J}}{\mathrm{gm}} \\
& \mathrm{z}_{1}:=200 \cdot \mathrm{ft} \\
& \mathrm{z}_{2}:=15 \cdot \mathrm{ft} \\
& \mathrm{z}_{3}:=6.7 \cdot \mathrm{ft} \\
& \mathrm{D}=\mathrm{z} \cdot \sqrt[3]{\mathrm{W}_{\mathrm{TNT}}} \\
& \mathrm{W}_{\mathrm{tnt}}:=\frac{\mathrm{E}_{\mathrm{Ba}}}{\mathrm{E}_{\mathrm{TNT}}}=2.828 \times 10^{-4} \mathrm{~kg} \\
& \mathrm{~W}_{\mathrm{TNT}}:=\frac{\mathrm{W}_{\mathrm{tnt}}}{\mathrm{kg}}=2.828 \times 10^{-4} \\
& \mathrm{D}_{1}:=\mathrm{z}_{1} \cdot \sqrt[3]{\mathrm{W}_{\mathrm{TNT}}}=13 \cdot \mathrm{ft} \\
& \mathrm{D}_{2}:=\mathrm{z}_{2} \cdot \sqrt[3]{\mathrm{W}_{\mathrm{TNT}}}=12 \cdot \mathrm{in} \\
& \mathrm{D}_{3}:=\mathrm{z}_{3} \cdot \sqrt[3]{\mathrm{W}_{\mathrm{TNT}}}=5 \cdot \mathrm{in}
\end{aligned}
$$




\subsubsection{1 lbf-ft Blast Wave}

The blast wave for an over-pressure event in a system with $1 \mathrm{lbf}-\mathrm{ft}$ is:

$$
\begin{aligned}
& \mathrm{E}_{\mathrm{Ba} 1}:=1 \cdot \mathrm{lbf} \cdot \mathrm{ft} \\
& \mathrm{W}_{\mathrm{tnt} 1}:=\frac{\mathrm{E}_{\mathrm{Ba} 1}}{\mathrm{E}_{\mathrm{TNT}}}=2.796 \times 10^{-7} \mathrm{~kg} \\
& \mathrm{~W}_{\mathrm{TNT} 1}:=\frac{\mathrm{W}_{\mathrm{tnt} 1}}{\mathrm{~kg}}=2.796 \times 10^{-7} \\
& \mathrm{D}_{1 \mathrm{a}}:=\mathrm{z}_{1} \cdot \sqrt[3]{\mathrm{W}_{\mathrm{TNT} 1}}=16 \cdot \mathrm{in} \\
& \mathrm{D}_{2 \mathrm{a}}:=\mathrm{z}_{2} \cdot \sqrt[3]{\mathrm{W}_{\mathrm{TNT} 1}}=1.2 \cdot \mathrm{in} \\
& \mathrm{D}_{3 \mathrm{a}}:=\mathrm{z}_{3} \cdot \sqrt[3]{\mathrm{W}_{\mathrm{TNT} 1}}=0.5 \cdot \mathrm{in}
\end{aligned}
$$$$
\text { Energy }
$$

Energy Equivalent in TNT, kg
Energy Equivalent in TNT, Unitless Conversion

Maximum distance for debris and missile damage.

Maximum distance for eardrum rupture.

Maximum distance for lung damage.

\subsubsection{0 lbf-ft Blast Wave}

The blast wave for an over-pressure event in a system with 500 lbf-ft is:

$$
\begin{array}{ll}
\mathrm{E}_{\mathrm{Ba} 2}:=500 \cdot \mathrm{lbf} \cdot \mathrm{ft} & \begin{array}{l}
\text { Energy } \\
\text { Energy Equivalent in TNT, kg }
\end{array} \\
\mathrm{W}_{\mathrm{tnt} 2}:=\frac{\mathrm{E}_{\mathrm{Ba} 2}}{\mathrm{E}_{\mathrm{TNT}}}=1.398 \times 10^{-4} \mathrm{~kg} & \text { Energy Equivalent in TNT, Unitless Conversion } \\
\mathrm{W}_{\mathrm{TNT} 2}:=\frac{\mathrm{W}_{\mathrm{tnt} 2}}{\mathrm{~kg}}=1.398 \times 10^{-4} & \text { Maximum distance for debris and missile damage. } \\
\mathrm{D}_{1 \mathrm{~b}}:=\mathrm{z}_{1} \cdot \sqrt[3]{\mathrm{W}_{\mathrm{TNT} 2}}=10.4 \cdot \mathrm{ft} & \text { Maximum distance for eardrum rupture. } \\
\mathrm{D}_{2 \mathrm{~b}}:=\mathrm{z}_{2} \cdot \sqrt[3]{\mathrm{W}_{\mathrm{TNT} 2}}=9 \cdot \mathrm{in} & \text { Maximum distance for lung damage. } \\
\mathrm{D}_{3 \mathrm{~b}}:=\mathrm{z}_{3} \cdot \sqrt[3]{\mathrm{W}_{\mathrm{TNT} 2}}=4 \cdot \mathrm{in} &
\end{array}
$$

\subsection{4 $10000 \mathrm{lbf}-\mathrm{ft}$ Blast Wave}

The blast wave for an over-pressure event in a system with 10000 lbf-ft is:

$$
\begin{aligned}
& \mathrm{E}_{\mathrm{Ba} 3}:=10000 \cdot \mathrm{lbf} \cdot \mathrm{ft} \\
& \mathrm{W}_{\mathrm{tnt} 3}:=\frac{\mathrm{E}_{\mathrm{Ba} 3}}{\mathrm{E}_{\mathrm{TNT}}}=2.796 \times 10^{-3} \mathrm{~kg} \\
& \mathrm{~W}_{\mathrm{TNT} 3}:=\frac{\mathrm{W}_{\mathrm{tnt} 3}}{\mathrm{~kg}}=2.796 \times 10^{-3} \\
& \mathrm{D}_{1 \mathrm{c}}:=\mathrm{z}_{1} \cdot \sqrt[3]{\mathrm{W}_{\mathrm{TNT} 3}}=28 \cdot \mathrm{ft} \\
& \mathrm{D}_{2 \mathrm{c}}:=\mathrm{z}_{2} \cdot \sqrt[3]{\mathrm{W}_{\mathrm{TNT} 3}}=25 \cdot \mathrm{in} \\
& \mathrm{D}_{3 \mathrm{C}}:=\mathrm{z}_{3} \cdot \sqrt[3]{\mathrm{W}_{\mathrm{TNT} 3}}=11 \cdot \mathrm{in}
\end{aligned}
$$

Energy

Energy Equivalent in TNT, kg

Energy Equivalent in TNT, Unitless Conversion

Maximum distance for debris and missile damage.

Maximum distance for eardrum rupture.

Maximum distance for lung damage. 


\subsection{Comparative Stored Energy}

To get an understanding of stored energy in real world applications, a variety of items encountered in daily life and laboratory operations are evaluated in Table 4.2.

Table 4.2. Stored Energy of Everyday Items

\begin{tabular}{|c|c|c|c|c|c|}
\hline Item & $\begin{array}{c}\text { Volume } \\
\left(\mathrm{ft}^{\wedge} 3\right)\end{array}$ & Gas & $\begin{array}{c}\text { Pressure } \\
\text { (psig) }\end{array}$ & $\begin{array}{c}\text { Stored Energy } \\
\text { (lbf-ft) }\end{array}$ & Method \\
\hline Compressed Gas Cylinder & 1.42 & Air & 2500 & 982,500 & Stored Energy Spreadsheet \\
\hline Standard Air Compressor, 50 gal & 6.68 & Air & 125 & 159,000 & Stored Energy Spreadsheet \\
\hline Standard Air Compressor, 20 gal & 2.67 & Air & 125 & 64,000 & Stored Energy Spreadsheet \\
\hline $\begin{array}{l}\text { Propane Tank (grill, compressed gas expansion } \\
\text { only) }\end{array}$ & 0.63 & Propane & 200 & 35,000 & Stored Energy Spreadsheet \\
\hline Paint Ball Tank (20 oz) & 0.02 & Air & 3000 & 21,300 & Stored Energy Spreadsheet \\
\hline M-80 (2.5 grams of powder) & N/A & $\mathrm{N} / \mathrm{A}$ & N/A & 17,000 & See Appendix A \\
\hline $\begin{array}{l}\text { State Limit for Third Party Inspection of } \\
\text { ASME Coded Vessel }\end{array}$ & 5 & Air & 15 & 9,700 & Stored Energy Spreadsheet \\
\hline Car Tire & 0.97 & Air & 35 & 5100 & Stored Energy Spreadsheet \\
\hline Mountain Bike Tire & 0.2 & Air & 65 & 2,230 & Stored Energy Spreadsheet \\
\hline CO2 2L Pop Bottle Bomb & 0.05 & $\mathrm{CO} 2$ & 150 & 1,750 & $\begin{array}{c}\text { Stored Energy Spreadsheet and } \\
\text { Appendix A }\end{array}$ \\
\hline Typical CO2 Cartridge (16 gram) & 0.0047 & $\mathrm{CO} 2$ & 900 & 1,263 & Stored Energy Spreadsheet \\
\hline STORED ENERGY LIMIT & & & & 1000 & \\
\hline BMX Bike Tire & 0.11 & Air & 50 & 915 & Stored Energy Spreadsheet \\
\hline Road Bike Tire & 0.04 & Air & 110 & 820 & Stored Energy Spreadsheet \\
\hline Typical CO2 Cartridge (12 gram) & 0.0058 & $\mathrm{CO} 2$ & 420 & 650 & Stored Energy Spreadsheet \\
\hline Typical Firecracker (50 mg powder) & $\mathrm{N} / \mathrm{A}$ & $\mathrm{N} / \mathrm{A}$ & N/A & 340 & See Appendix A \\
\hline Dust Spray Can & 0.02 & Mix & 85 & 335 & Stored Energy Spreadsheet \\
\hline Soccer Ball & 0.215 & Air & 12 & 320 & Stored Energy Spreadsheet \\
\hline Party Balloon & 2.42 & Air & 1 & 255 & Stored Energy Spreadsheet \\
\hline Basketball & 0.26 & Air & 8 & 250 & Stored Energy Spreadsheet \\
\hline
\end{tabular}




\subsection{Tabulated Results}

The following results are tabulated from the calculations performed above.

Table 4.3. Tabulated Stored Energy Analysis Results

\begin{tabular}{|l|c|c|c|}
\hline \multirow{2}{*}{ Description } & \multicolumn{3}{|c|}{ Worst Case Distance for Possible } \\
\cline { 2 - 4 } & $\begin{array}{c}\text { Missile/Debris } \\
\text { Damage }\end{array}$ & $\begin{array}{c}\text { Ear Drum } \\
\text { Rupture }\end{array}$ & $\begin{array}{c}\text { Lung } \\
\text { Hemorrhage* }\end{array}$ \\
\hline $\begin{array}{l}\text { Ideal Gas Expansion; P1V1 = P2V2 @ 1000 } \\
\text { lbf-ft }\end{array}$ & $>1 \mathrm{ft}$ & $\sim 6$ in & $\sim 3$ in \\
\hline 1000 lbf-ft Blast Wave & $13 \mathrm{ft}$ & $12 \mathrm{in}$ & 5 in \\
\hline 1 lbf-ft Blast Wave & $16 \mathrm{in}$ & $1.2 \mathrm{in}$ & 0.5 in \\
\hline 500 lbf-ft Blast Wave & $10.4 \mathrm{ft}$ & $9 \mathrm{in}$ & 4 in \\
\hline 10000 lbf-ft Blast Wave & $28 \mathrm{ft}$ & $25 \mathrm{in}$ & 11 in \\
\hline
\end{tabular}

*These values are not considered realistic at such short distances.

\begin{tabular}{|l|c|}
\hline Description of Item* & Stored Energy \\
\hline Compressed Gas Cylinder & $982,500 \mathrm{lbf}-\mathrm{ft}$ \\
\hline WA State Limit for $3^{\text {rd }}$ Party Inspection of ASME Coded Vessel & $9,700 \mathrm{lbf}-\mathrm{ft}$ \\
\hline PNNL Stored Energy Limit & $1,000 \mathrm{lbf}-\mathrm{ft}$ \\
\hline Typical CO2 Cartridge (12 gram) & $650 \mathrm{lbf}-\mathrm{ft}$ \\
\hline Party Balloon & $255 \mathrm{lbf}-\mathrm{ft}$ \\
\hline
\end{tabular}

*See Table 4.2 for the stored energy of additional items. 



\subsection{Conclusions}

Based upon a review of applicable literature and the supporting calculations performed, the following conclusions were derived:

1. Stored energy is an appropriate method to determine the potential hazards of an overpressure event.

2. Calculating Stored Energy:

a. The Baker equation is an acceptable method to determine the stored energy of compressed gases. Although Brode is identified by Lees' and the Fire Protection Handbook as the preferred method for determining compressed gas stored energy, PNNL will continue to use Baker. Baker is considered the best alternative, and is being used by PNNL, INL, and historically by LANL and LLNL. A switch from Baker to Brode would highly impact operations, confuse the pressure safety stored-energy relation, and add little value. Furthermore, the use of stored energy is inherently conservative because the Baker model is a reversible (isentropic expansion) process.

b. The stored energy in liquid systems shall continue being calculated using fluid compressibility.

c. For non-ideal gases, cryogens, and flashing liquids the use of enthalpy and internal energy tables shall be utilized.

3. The use of a 1000 lbf-ft energy limit is consistent with an acceptable level of risk. The conservative blast wave equation shows that a possible personnel injury could occur $\sim 1$ foot away from a pressure release; however, this stored energy is no greater than the energy encountered by items used every day in our homes. $1000 \mathrm{lbf}-\mathrm{ft}$ is also nearly 10 times less than the stored energy at which the State of Washington requires inspections for ASME Coded Vessels. Furthermore, the culture of safety glass use, wearing proper attire in laboratories, and minimizing the use of brittle materials all mitigate the probability of missile debris causing injury during an overpressure event. Lastly, the $1000 \mathrm{lbf}-\mathrm{ft}$ limit is consistent with perceived hazards based upon everyday experience with common household and laboratory items. During pressure systems reviews, engineering judgment is consistent with the 1000 lbf-ft limit as a practical measure of risk. 



\subsection{Recommendations}

During the development of this analysis, certain aspects regarding PNNL Pressures Safety Program were deemed to have a potential weakness. Recommendations to remedy these possible deficiencies are listed below. Each recommendation will be assigned as an Action Tracking System (ATS) Item to the Pressure Systems Engineer, and tracked through closure.

1. Implement the use of enthalpy differentials for non-ideal gas, vapor, and flashing liquid. This should be clearly identified in the Pressure Systems subject area and the Engineering Standard: Pressure/Vacuum Systems.

2. Use of fluids that do not fall into the "non-hazardous" category should require an added stage of rigor beyond a pressure safety review. The use of a Chemical Process Permit should be evaluated to ensure hazardous fluid systems below the risk limit are being safely designed.

3. Ensure that brittle materials are not used for compressed gas service. Guidance should be added to the Pressure Systems subject area and the Engineering Standard: Pressure/Vacuum Systems. Note: Glass systems already have a category in the Pressure Systems subject area, and other items, such as PVC and cast fittings, are not allowed for compressed gas service. 



\subsection{References}

10 CFR 851. 2006. Worker Safety and Health Program. Code of Federal Regulations, U.S. Department of Energy.

American Society of Mechanical Engineers. 2008. PCC-2 - 2008 Repair of Pressure Equipment and Piping. American Society of Mechanical Engineers, New York, New York.

Lawrence Livermore National Laboratory. 2009. Part 18.2, “Pressure Vessel and System Design.” In Lawrence Livermore National Laboratory Environment, Safety and Health Manual. Lawrence Livermore National Laboratory, Livermore, California.

Lindeburg M. 2001. Mechanical Engineering Reference Manual (11 ${ }^{\text {th }}$ Edition). Professional Publications, Inc., Belmont, California.

Los Alamos National Laboratory. 2003. Pressure, Vacuum, and Cryogenic Systems. P101-34, Los Alamos National Laboratory, Los Alamos, New Mexico.

Mannan S, ed. 2005. Volume 2, Chapter 17, “Explosions.” In Lee's Loss Prevention in the Process Industries ( $3^{\text {rd }}$ Edition). Elsevier Butterwoth-Heinmann, Burlington, Massachusetts.

Paulsen SS. 2006. Pressure Systems Subject Area, PNNL Standards Based Management System. Pacific Northwest National Laboratory, Richland, Washington.

Zalosh R. 2008. “Explosions.” Section 2, Chapter 8 in Fire Protection Handbook, Volumes I and II (20th Edition), eds Cote AE, CC Grant, JR Hall Jr, RE Solomon, PA Powell, RL Alpert, RP Benedetti, SM Clary, MT Conroy, RLP Custer, C Dubay, JA Granito, DR Hague, JR Hall Jr, GE Harrington, E Kirtley, LJ Mattern, G Proulx, MT Puchovsky, CH Rivkin, SF Sawyer, RAB Spencer, G Tokle, and RJ Vondrasek, National Fire Protection Association, Quincy, Massachusetts. 

Appendix A

Internet Articles Regarding Flash Powder Energy 



\title{
Appendix A: Internet Articles Regarding Flash Powder Energy
}

\author{
What is an "M-80," anyway? \\ http://www.fireworksland.com/html/m80.html
}

“...Up until 1966, large firecrackers such as M-80s and cherry bombs were legal in the United States, and anyone could buy them and shoot them off. If you look through old fireworks catalogs from the 1930s, '40s and '50s, you will see these and even larger firecrackers advertised, all of them perfectly legal at that time. But it all ended in 1966. The Child Protection Act, passed by the U.S. Congress in 1966, specifically banned these devices. In 1976, the federal regulations were rewritten specifying a limit of 50 milligrams of pyrotechnic composition for any firecracker sold to the public in the United States, and that limit is still in effect today. It doesn't matter what they look like or what they are shaped like - ground firecrackers can only contain 50 milligrams of pyrotechnic content per cracker (Emphasis added). (Aerial "reports," which are contained within aerial devices such as rockets and shells, can contain up to 129.6 milligrams of composition per report.)..."

\section{The Relative Explosive Power of an M-80 vs. a Dry Ice Bomb}

http://dryicebomb.info/m-80 explosive power.html

\section{Conclusion}

An M-80 is 33 times more powerful than a dry ice bomb.

\section{Explosives}

An explosion is the sudden release of energy, and an explosive is a device that stores energy and allows its sudden release. The power of an explosive is directly proportional to the amount of stored energy that it releases. The stored energy of explosive devices is straightforward to estimate. This page compares the stored energy of a bottle bomb with that of an M-80, a common firecracker.

Calculations show that a bottle bomb releases a tiny fraction of the energy of an M80, and that it is therefore far less dangerous.

\section{Dry Ice Bombs}

A dry ice bomb, also called a bottle bomb, usually consists of a 2-liter plastic soda bottle filled partially with dry ice and water. The water heats the dry ice and causes it to sublimate into gaseous $\mathrm{CO}_{2}$. When the pressure from the $\mathrm{CO}_{2}$ reaches the bursting pressure of the bottle, the bottle explodes, releasing the available energy of the pressurized gas (there is no combustion, no heat, and no fire). The energy stored in the bottle before it ruptures is the product of the pressure of the $\mathrm{CO}_{2}$ gas in the bottle and the volume of the bottle. The energy in that same $\mathrm{CO}_{2}$ after the rupture is product of its pressure and the volume of the same molecules of $\mathrm{CO}_{2}$ that were in the bottle before it ruptured. The difference between these two energies is the energy available to make a boom or to cause damage. The gas volume before rupture is the volume of the bottle less the volume of the water and dry ice placed inside the bottle.

For purposes of these estimates, the volume used is $75 \%$ the volume of the bottle, leaving $25 \%$ of the volume for water and dry ice. Since the burst pressure depends only on the strength of the plastic bottle, the released energy does not depend on the amount of dry ice in the bottle (other than that due to the loss of volume in the bottle taken up by the dry ice and water). The Coca Cola web site states that the bursting pressure of a 2-liter bottle is 150 PSI. After converting to the appropriate units, the volume of $\mathrm{CO}_{2}$ is $0.0015 \mathrm{~m}^{3}$, the pressure is about $1.1 \mathrm{MPa}$ (converting $150 \mathrm{PSI}$ into metric), giving an energy in the compressed $\mathrm{CO}_{2}$ the instant before rupture as 1672 Joules. 
After the bottle ruptures, the gas expands adiabatically (this means that it does not have time to exchange heat with its surroundings), so the volume increases by the following factor

(Pressure before rupture/pressure after rupture) ${ }^{1 / \gamma}$.

(see http://hyperphysics.phy-astr.gsu.edu/hbase/thermo/adiab.htm and

http://encyclopedia.airliquide.com/encyclopedia.asp?GasID=26)

With a pressure ratio of about 11 , and using $\gamma$ for $\mathrm{CO} 2,1.29$, the volume increases by a factor of 6.4 . The volume of the $\mathrm{CO} 2$ is now $0.0096 \mathrm{~m} 3$, the pressure is $0.101 \mathrm{MPa}$, giving an energy in the CO2 of 975 Joules.

Thus the energy released at rupture is $1672-975=697$ Joules.

Note that there is no heat generated or combustion or chemical change with a bottle bomb. There is no opportunity for fire and no opportunity for burns. The water in the bottle would, if anything, contribute toward the extinguishing of any fire that happened to be present. There may be a fog produced that looks like smoke (dry ice is commonly used in fog makers).

\section{M-80 firecracker}

M-80 firecrackers were popular during the 50's and 60's and are now illegal under federal law

(http://www.cdc.gov/NCIPC/factsheets/fworks.htm). They were intended to make sound like a gun being fired. They are paper tubes about 11/2 inches long and 9/16 inch in diameter filled with 2.5 to 3 grams (38 to 46 grains) of flash powder with a fuse at the side of the tube (http://www.pyrowiki.com/). The stored energy of an M-80 is estimated from the energy density of the flash powder and its mass. The energy density of flash powder is $2200 \mathrm{cal} / \mathrm{g}=9196 \mathrm{Joules} / \mathrm{g}$ (http://www.powerlabs.org/chemlabs/deflagrants.htm).

Using the $2.5 \mathrm{~g}$ mass of the flash powder gives the energy in an M-80 of 22,990 Joules, some 33 times that of an exploding bottle.

Note that the energy release of M-80's involves combustion. Thus an M-80 could cause burns and fire and all the dangers associated with fire. 


\section{Distribution}

No. of

Copies

\# Name

Organization

Address

City, State and ZIP Code

\# Organization

Address

City, State and ZIP Code

Name

Name

Name

Name

Name (\#)

\# Name

Organization

Address

City, State and ZIP Code
No. of

Copies

\section{\# Foreign Distribution}

\# Name

Organization

Address

Address line 2

COUNTRY

\# Local Distribution

Pacific Northwest National Laboratory

Name

Name

Name

Name

Name
Mailstop

Mailstop

Mailstop

Mailstop

(PDF) 




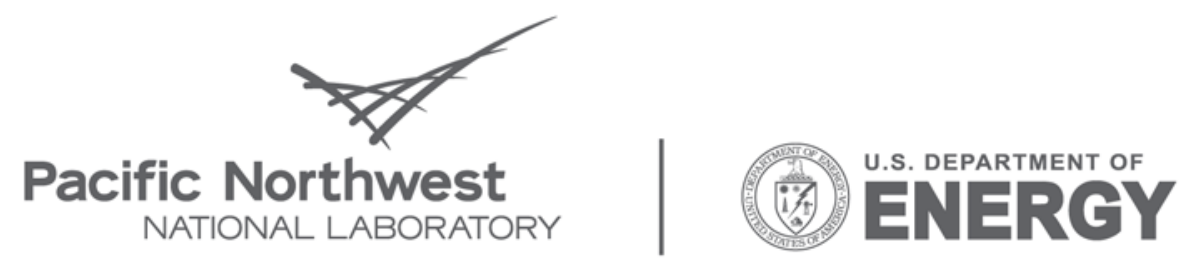

Proudly Operated by Battelle Since 1965

902 Battelle Boulevard

P.O. Box 999

Richland, WA 99352

1-888-375-PNNL (7665)

www.pnl.gov 